this fraction showed a low mean delta value : $E 1 \mathrm{~cm} / 1 \%=$ 0.55 .

Discussion. The concept of a purely biological antioxidant activity of vitamin $\mathrm{E}$, and an associated function of selenoamino acids as free radicals scavengers and peroxide descomposers, has suggested lipid peroxidation in vivo as the original alteration in the pathogenesis of dietary liver necrosis ${ }^{3,1}$. Cellular membranes would be damaged, since they are largely composed by polyunsaturated fatty acids.

A large part of the argument in support of the lipid peroxidation hypothesis derives either from experiments in vitro on the properties of antioxidants, or comparative studies with other experimental models, such as radiation damage and ageing processes. A protective action of antioxidants compounds like DPPD, replacing the vitamin $\mathrm{E}$ in the diet, has been advocated as direct evidence for the lipid peroxidation mechanism ${ }^{9}$. However, studies conducted by other authors failed to confirm the alternative action of vitamin $\mathrm{E}$ and structurally different antioxidants as related to prevention of lipid peroxidation ${ }^{10,11}$. It is interesting to note that in other non-toxic cellular necrosis, like renal necrosis in choline deficient rats, in which lipid peroxidation in vivo has been demonstrated, DPPD leads to a decrease of the renal lesions while vitamin $E$ fails to exert a similar protective action ${ }^{12}$. Critical examinations of the lipid peroxidation hypothesis have concluded that the peroxide content in rat liver is not altered by the addition of vitamin $\mathrm{E}$ to the diet 11 .

The significance of peroxides detected by the widely used reaction of the thiobarbituric acid (TBA) with malonaldehydes, has been setiously objected to as evidence of the existence of lipid peroxidation in living tissues. It is presently believed that malonaldehyde is metabolized in vivo through mitochondrial pathways, and therefore the TBA reaction would depend on peroxides formed in vitro during the procedure ${ }^{6}$.

The results reported here, obtained by the method of detection of diene conjugates, indicate that there is no evidence of lipid peroxidation during the different stages of the prenecrotic period, except for the plasma membrane fraction at 21 days. Since it has been previously demon- strated ${ }^{13}$ that the plasma membrane of liver cells presents enzymatic alterations at 14 days, this positive result must be considered an expression of a late alteration, unrelated to the causal mechanism of induction of the cellular injury. Furthermore, the existence of microscopic necrotic changes in some of the livers in the prenecrotic period cannot be excluded. Slight contamination of the microsomal fractions with plasma membrane might account for the atypical curves observed in some experiments.

The present results stress the need for alternative explanations. Mild lipoperoxidation damage comes too late in the sequence of events leading to cellular necrosis to account for its pathogenesis.

Zusammenfassung. Es wird festgestellt, dass der Einfluss von Lipidperoxyden nicht für die Entstehung gewisser Formen der Lebernekrose verantwortlich gemacht werden können.

\section{E. A. MAchado ${ }^{14}$ and F. Hamilton ${ }^{15}$}

Centro de Patologia Experimental, Facultad de Medicina, J.E. Uriburn 950, Universidad de Buenos Aives, Buenos Aires (Argentina), and

The Research Institute of The Hospital for Sick Children, Toronto, (Ontario, Canada), 6 February 1973.

${ }^{3}$ A. L. Tappel, Fedn Proc. 24, 73 (1965).

13 K. Schwarz, in Liver Function (Ed. R. W. BraUeR; American Institute of Biological Sciences 1958); p. 387.

:1 J. Bunyan, E. A. Murrell, J. Green and A. T. Diplock, Br. J. Nutr. 21, 475 (1967)

12 A. J. Monserrat, A. K. Ghoshal, W. S. Hartroft and E. A. Porta, Am. J. Path. 55, 163 (1969).

13 E. A. Machado, E. A. Porta, W. S. Hartroft, and F. Hamilton Lab. Invest. 24, 13 (1971).

${ }^{14} \mathrm{New}$ address: The University of Tennessee Memorial Research Center and Hospital, Knoxville (Tennessee 37920, USA).

${ }_{15}$ Acknowledgments. The authors wish to thank Dr. A. K. Ghoshal for many valuable discussions.

\title{
Identification of Two New Metabolites of Caffeine in the Rat Urine
}

During our recent studies ${ }^{1}$ on the metabolism of caffeine${ }^{3} \mathrm{H}$ in the rat, we reported the isolation of the following metabolites from the chloroform-methanol (9:1) extract ${ }^{2}$ of the urine: theophylline $(1.2 \%)$, theobromine $(5.1 \%)$, paraxanthine $(8.8 \%)$ and trace amounts of $1,3,7$-trimethyluric acid and 3-methyluric acid. In addition, two unidentified metabolites, $\mathrm{A}(11.4 \%)$ and $\mathrm{B}(1.3 \%)$, were isolated. The present communication deals with the structure elucidation of these 2 new metabolites of caffeine

The thin-layer chromatographic (TLC) and spectral (IR, UV and mass) characteristics of the isolated metabolites $A$ and $B$ were found to be markedly different from those of the known mono-, di-, and trimethyl derivatives of xanthine and uric acid ${ }^{1,3}$. The major metabolite $A$ appeared to be a polar compound. It readily dehydrated to caffeine under TLC and gas chromatographymass spectrometric (GC column: $1 \%-\mathrm{OV}-17$, temperature $190^{\circ} \mathrm{C}$ ) conditions and as such it is difficult to isolate this metabolite in pure form. We have assigned structure I (1, 3, 7-trimethyldihydrouric acid) to the metabolite $A$, primarily on the basis of the mass spectra of the metabolite [peaks at m/e: 212 $\left(\mathrm{M}^{+}\right), 194\left(\mathrm{M}-\mathrm{H}_{2} \mathrm{O}\right), 184\left(\mathrm{M}-\mathrm{CO}, m^{*} 159.5\right), 169\left(184-\mathrm{CH}_{3}\right.$, $m * 155), 142(169 \cdot \mathrm{HCN}, m * 119.5)$ and $109\left(194-\mathrm{CH}_{3} \mathrm{NCO}\right.$ and $\mathrm{CO})$ ] and its ditrimethylsilyl derivative II [peaks at $m / e: 356\left(\mathrm{M}^{+}\right)$and $\left.341\left(\mathrm{M}-\mathrm{CH}_{3}\right)\right]$. Proton nuclear magnetic resonance analysis $\left(\mathrm{CDCl}_{3}\right.$ solvent) indicated that in solution, metabolite $\mathrm{A}$ appears to be in equilibrium with its open-chain, $N$-formyl analog III. About $25 \%$ caffeine (IV) was also found to be present in the solution (Scheme I). Oxidation at the 8 position of the purine ring to yield 8 hydroxy derivatives has been previously observed in the rat with guanine-3-oxide ${ }^{4}$ and purine ${ }^{5}$ itself.

1 K. L. Khanna, G. S. Rao and H. H. Cornish, Toxic. appl. Pharmac. $23,720(1972)$

2 The chloroform-methanol $(9: 1)$ extract of the urine accounted for about $35 \%$ of the ingested radioactive caffeine out of which about $9 \%$ was found to be unchanged caffeine.

${ }^{3}$ G. S. Rao, K. L. Khanna and H. H. Cornish, J. pharm. Sci. $61,1822(1972)$.

${ }^{4}$ G. Stöhrer and G. B. Brown, J. biol. Chem. 244, 2494 (1969).

${ }^{5}$ M. P. Gordon, O. M. Interieri and G. B. Brown, J. biol. Chem. $229,641(1957)$. 
Scheme I.<smiles>Cn1c(=O)c2c([nH]c(=[18O])n2C)n(C)c1=O</smiles>

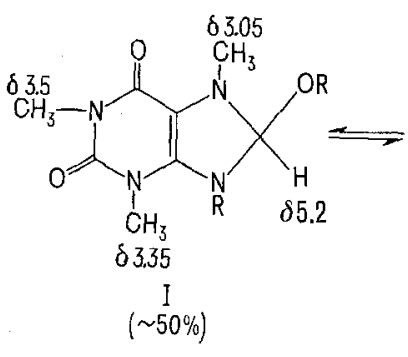<smiles>CN(C(=O)[18OH])c1c(N)n(C)c(=O)n(C(C)(C)C)c1=O</smiles>

I. $\mathrm{R}=\mathrm{H}$

II. $\mathrm{R}=\mathrm{TMS}$

Structure V (3, 6, 8-trimethylallantoin) may be assigned to the minor metabolite $B$ based on its mass spectral fragmentation pattern [peaks at $m / e: 200\left(\mathrm{M}^{+}\right), 143$ (M-CH $\left.{ }_{3} \mathrm{NCO}, m * 102.2\right)$ and 115 (M-CO)]. The metabolite $B$ gave positive reaction to the Young-ConwAY test ${ }^{6}$ which confirmed that it is a derivative of allantoin. Allantoin is known to be the major metabolite of purine, xanthine, and hypoxanthine in the rat ${ }^{5,7}$. FRANKE and HAHN ${ }^{8}$ have reported earlier that certain microorganisms metabolize methylxanthines, such as caffeine, to methylallantoin. DRYhURST and HANSEN ${ }^{9}$ have recently identified 3 , 6, 8-trimethyl allantoin (V) as a product of electrochemical oxidation of caffeine. Photochemical oxidation of methylxanthines is also known to lead to methylallantoins ${ }^{10}$.

Scheme II describes the proposed biotransformations of caffeine in the rat. About $9 \%$ of the unchanged caffeine<smiles>CNC(=O)N(C)C1NC(=O)N(C)C1=O</smiles>

was recovered from the chloroform-methanol (9:1) extract of the urine. The 3 mono- $N$-dealkylated products, theobromine, paraxanthine and theophylline, isolated from the chloroform-methanol extract account for about $15 \%$ of the ingested radioactive caffeine. Hydroxylation followed by reduction of caffeine apparently leads to the isolated major metabolite, 1, 3, 7-trimethyldihydrouric acid (I). Dehydrogenation of $I$ gives 1, 3, 7-trimethyluric acid which then undergoes $N$-dealkylations to form 3-methyluric acid. However, the more favored mode of degradation

${ }^{6}$ E. G. Young and C. F. Conway, J. biol. Chem. 142, 839 (1942). Sequential base and acid hydrolyses of allantoin and its $N$-methyl derivatives quantitatively yield glyoxylic acid which can then be readily detected by the development of the characteristic chromophore, $\lambda \max .515 \mathrm{~nm}$ under the Rimini-Schryver reaction conditions.

' H. Getler, P. M. Roli, J. F. Tinker and G. B. Brown, J. biol. Chem. 778, 259 (1949).

${ }^{8}$ W. Fran Ke and G. E. Hahn, Hoppe-Seyler's Z. physiol. Chem. $301,90(1955)$.

${ }^{9}$ G. Dryhurst and B. H. Hansen, J. electroanalyt. Chem. 30, 407 (1971).

10 I. R. Politzer, G. W. Griffin and J. L. Laseter, Chem. biol. Interactions 3, 73 (1971).

Scheme II.

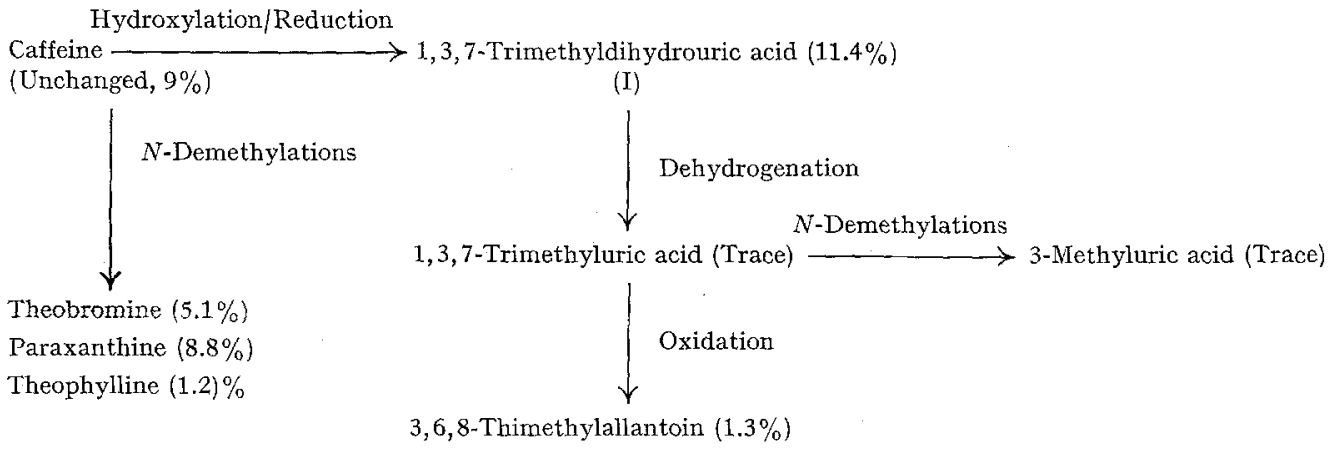

(V)

Oxidation

$\downarrow$

1,6,8-Trimethylallantoic acid

Hydrolysis 
of trimethyluric acid appears to be the oxidative ring opening of the pyrimidine ring to form 3, 6, 8-trimethylallantoin (V) which can then be further oxidized and hydrolized to more polar products such as 1, 6, 8-trimethylallantoic acid, glyoxylic acid, and mono-, and dimethylureas.

The hitherto known metabilites of caffeine viz, methylxanthines and methyluric acids, isolated from the urine of experimental animals represent only a fraction of the urinary metabolites of caffeine ${ }^{11-13}$ Our results seem to explain the observed difficulty in recovering caffeine metabolites from the urine since methylated allantoins, allantoic acids and urea derivatives are highly polar and not easily extractable. Also these polar compounds may constitute the unidentified metabolites encountered by earlier investigators ${ }^{14}$.

Résumé. L'acide 1, 3, 7-triméthyldihydro-urique et la 3, 6, 8-triméthylallantoine ont été identifiés comme métabolites nouveaux de la cafféine dans l'urine de rat.

\section{G. S. RaO ${ }^{15}$, K. L. Khanna and H. H. Cornish}

Department of Environmental and Industrial Health, School of Public Health, The University of Michigan, Ann Arbor (Michigan 48104, USA), 12 March 1973.

\section{Effect of Medium $\mathrm{pH}$ on $p$-Aminohippurate Accumulation by Slices of Rat Renal Cortex ${ }^{1}$}

Several techniques have been employed to study the transport of organic ions by the kidney, including clearance $^{2,3}$, micropuncture and microperfusion 4,5 and isolated tubules ${ }^{6,7}$. Probably the most widely used technique is the in vitro slice method of CRoss and TAGGART ${ }^{8}$. Even though the method is routine in many laboratories optimal conditions for incubation have not been completely elucidated. For instance, CRoss and TAGGART $^{8}$ observed that accumulation of the organic acid p-aminohippurate (PAH) by rabbit kidney cortical slices was dependent upon temperature and oxygen but was independent of $\mathrm{pH}$ over a relatively narrow range ( $\mathrm{pH}$ 7.0-7.8). However, Copenhaver and Davis ${ }^{9}$ found that over a wider $\mathrm{pH}$ range $(5.0-12.0)$ the greatest accumulation of $\mathrm{PAH}$ by rabbit renal cortical slices was at $\mathrm{pH} 8.1$ to 8.3 . In contrast, Ross et al. ${ }^{10}$ found the greatest accumulation of PAH by dog renal cortical slices to be at pH 7.4. To our knowledge comparable studies have not been conducted in tissue from the rat. Inasmuch as rat tissue is extensively employed for studies of renal transport in this laboratory, it was of interest to determine the effect of $\mathrm{pH}$ upon PAH accumulation by renal cortical

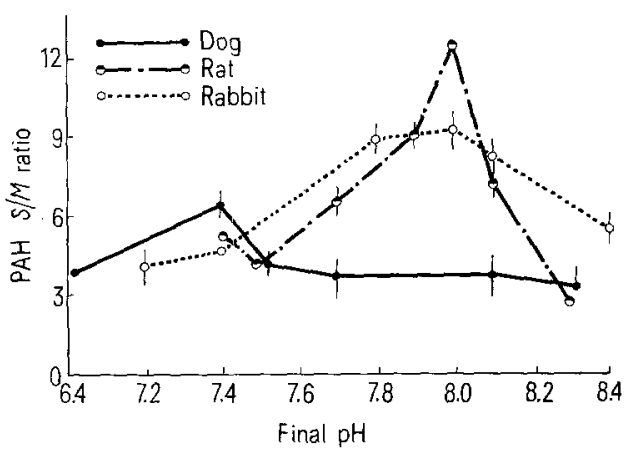

Effect of medium $\mathrm{pH}$ on $\mathrm{PAH}$ accumulation $(S / M)$. $\mathrm{pH}$ values shown are those at the end of 90 min incubation. Each point represents the mean ( $\pm \mathrm{SE}$ ) obtained in 5 duplicated experiments. When no vertical line is shown the variation is within the radius of the circle. In individual experiments a single dog or rabbit was used. For rat experiments, the kidneys of several animals were pooled and then treated as one. slices from this species. For comparative purposes the effect of $\mathrm{pH}$ on $\mathrm{PAH}$ accumulation in rabbit and dog tissue was also determined.

Methods. Adult mongrel dogs, New Zealand rabbits and Sprague-Dawley rats were used in these studies. Dogs were anesthetized with pentobarbital sodium (30 mg/kg, i.v.); rabbits and rats were stunned by a blow on the head Kidneys were quickly removed, weighed and placed in ice-cold saline. Renal cortical slices were prepared free hand and briefly kept in cold saline until incubated. Slices (approximately $100 \mathrm{mg}$ ) were incubated for $90 \mathrm{~min}$ using either $0.1 M$ sodium phosphate buffer or $0.015 M$ 2amino-2-methyl-1, 3 propanediol (propanediol) buffer, in medium containing $7.4 \times 10^{-5} M$ PAH. All incubations were carried out in duplicate in a Dubnoff apparatus at $25^{\circ} \mathrm{C}$ under a gas phase of $100 \%$ oxygen.

The $\mathrm{pH}$ of the incubation medium was initially adjusted to values ranging from 6.0 to 9.0 . Renal cortical slices from individual dogs or rabbits were incubated in medium at several different initial $\mathrm{pH}$ values in each experiment. Kidney slices from 4 rats were pooled and treated as tissue from one animal. In the experiments with dog tissue phosphate buffer was used throughout the $\mathrm{pH}$ range, while propanediol was used in all rat and rabbit studies. Unless stated otherwise, the reported $\mathrm{pH}$ values are those measured after incubation. The final $\mathrm{pH}$ range was from 6.4 to 8.4. The effect of medium $\mathrm{pH}$ on the rate of PAH uptake was determined in phosphate buffer at initial $\mathrm{pH}$ values of 7.4,8.0 and 8.5. Slices of rat renal cortex were incubated for periods of time ranging from 5 to $30 \mathrm{~min}$.

${ }^{1}$ Supported in part by USPHS grant No. AM-10913.

G. H. Mudge and I. V. TAGGart, Am. J. Physiol. 161, 191 (1950).

${ }^{3}$ G. A. TANner and M. T. Isenberg, Am. J. Physiol. 219, 889 (1970).

${ }^{4}$ G. A. TAnner, Am. J. Physiol. 212, 1341 (1967).

5 P. Deetjen and H. Sonnenberg, Arch. ges. Physiol. 285, 35 (1965).

${ }^{6}$ M. B. Burg and J. OrLof F, Am. J. Physiol. 203, 327 (1962).

7 K. C. Huang and D. S. T. Lin, Am. J. Physiol. 208, 391 (1965).

8 R. J. Cross and J. V. Taggart, Am. J. Physiol. 761, 181 (1950).

${ }^{9}$ J. H. Copenhaver and J. R. Davis, Proc. Soc. exp. Biol. Med. 119, $611(1965)$.

${ }^{10}$ C. R. Ross, N. I. Pessah and A. Farah, J. Pharmac. exp. Ther. 160, 381 (1968). 